\title{
Sorption of phosphate onto mesoporous $\gamma$-alumina studied with in-situ ATR-FTIR spectroscopy
}

\author{
Ting-Ting Zheng ${ }^{1,2}$, Zhong-Xi Sun $^{1 *}$, Xiao-Fang Yang ${ }^{2,3}$ and Allan Holmgren ${ }^{2^{*}}$
}

\begin{abstract}
Background: Due to the extensive use of phosphates in industry, agriculture and households, the phosphate - $\gamma$-alumina interactions are important for understanding its detrimental contribution to eutrophication in lakes and rivers. In situ Fourier transform infrared (FTIR) spectroscopy can provide more detailed information on the adsorbate-adsorbent interaction and the formation of hydrogen bonds.

Results: In situ ATR-FTIR spectroscopy was used to identify phosphate complexes adsorbed within the three-dimensional network of mesoporous $\gamma$-alumina at pH 4.1 and 9.0. The integrated intensity between $850 \mathrm{~cm}-1$ and $1250 \mathrm{~cm}-1$ was used as a relative measure of the amount of adsorbed phosphate. The integrated intensity proved to be about 3 times higher at pH 4.1 as compared with the corresponding intensity at pH 9.0. The adsorption of phosphate at the two pH conditions could be well described by the Langmuir adsorption isotherm at low concentrations and the empirical Freundlich adsorption isotherm for the whole concentration range, viz. 5 - $2000 \mu \mathrm{M}$.

Conclusions: From the band shape of infrared spectra at pH 4.1 and pH 9.0, it was proposed that the symmetry of the inner-sphere surface complex formed between phosphate and $\gamma$-alumina was $\mathrm{C} 1$ at the lower $\mathrm{pH}$ value, whilst the higher value (9.0) implied a surface complex with C2v or C1 symmetry. The difference in adsorbed amount of phosphate at the two $\mathrm{pH}$ values was ascribed to the reduced fraction of $\equiv \mathrm{AlOH} 2+$ surface sites and the increased fraction of $\equiv \mathrm{AlO}$ - sites upon increasing $\mathrm{pH}$ from 4 to 9.
\end{abstract}

\section{Background}

The concern about phosphate distribution in fresh water and soil is motivated by its detrimental contribution to eutrophication in lakes and rivers and the extensive use of phosphates in industry, agriculture and households [1,2]. The mobility of phosphate in soil and aquatic systems is largely determined by the reaction between phosphate and mineral surfaces [3,4]. Because of the abundance of aluminum and iron oxides in soil and sediment and their sorption reactivity to phosphate, the interaction of water with alumina and iron oxide [5-10] and the uptake of phosphate on various $\mathrm{Al}$ - and Fe-oxides (e.g., boehmite, gibbsite, goethite, ferrihydrite, hematite) has been studied extensively in the past decades by both macroscopic and spectroscopic

\footnotetext{
*Correspondence: sunzx@ujn.edu.cn; allan.r.holmgren@ltu.se

${ }^{1}$ School of Chemistry and Chemical Engineering, University of Jinan, 250022

Jinan, China

${ }^{2}$ Division of Chemical Engineering, Luleå University of Technology, S-971 87

Luleå, Sweden

Full list of author information is available at the end of the article
}

methods [11-30]. These investigations showed that phosphate inner-sphere complexes were formed at the metal oxide-water interface within a certain $\mathrm{pH}$ range. The type of surface complexes that may form, i.e. monodentate, bidentate mononuclear or binuclear and the degree of protonation varied with $\mathrm{pH}$. The surface coverage was both $\mathrm{pH}$ and contact time dependent and in addition to surface complexes also aluminum phosphate precipitates may form.

In situ or ex situ Fourier transform infrared (FTIR) spectroscopy can provide molecular scale information on phosphate configuration at the surface. The type of phosphate complexes that are formed in a fixed aqueous environment may be proposed based on the symmetry of the phosphate complex in combination with curve fitting analysis of the stretching $v_{3}$ vibration of phosphate. However, the bonding of phosphate to the metal oxide surface is difficult to unambiguously predict in detail due to the interplay between protonated surface species and hydrogen bonding. For instance, the protonated monodentate inner-sphere species
(C) Chemistry Central

C 2012 Zheng et al.; licensee Chemistry Central Ltd. This is an Open Access article distributed under the terms of the Creative Commons Attribution License (http://creativecommons.org/licenses/by/2.0), which permits unrestricted use, distribution, and reproduction in any medium, provided the original work is properly cited. 
$\left(\equiv \mathrm{AlOPO}_{2} \mathrm{OH}\right)$ can not be distinguished from monodentate species with a hydrogen bond to an adjacent surface hydroxyl group ( $\left.\equiv \mathrm{AlOPO}_{2} \mathrm{O}-\mathrm{HOAl} \equiv\right)$, since both species have equivalent low molecular symmetry. In spite of this limitation, FTIR spectroscopy has become one of the most useful tools in the analysis of phosphate species sorbed on solid surfaces. However, IR studies of phosphate sorption onto aluminum oxides are much less common than the corresponding studies on iron oxides, despite the wellknown strong interaction between phosphate and aluminum ions implying a high potential to affect the mobility of phosphate in soil systems containing aluminum oxides. Many of these studies were performed using exsitu methods [23] where spectroscopic data are collected under more or less dry conditions affecting the formation of hydrogen bonds and possibly the adsorbate-adsorbent interaction.

In this study the in-situ Attenuated Total Reflection (ATR) -FTIR spectroscopy technique was used implying that data were collected simultaneously as the adsorbate (orthophosphate) entered the detection volume of the adsorbent deposited on the ATR crystal. The detection volume consisted of a synthesized aluminum oxide with large surface area. A large surface area is advantageous in adsorption studies using the ATR method since the signal to noise ratio is improved implying a lower detection limit for a certain amount of adsorbent. The $\gamma$-alumina material used in this study improved the signal to noise due to its large surface area and mesoporous structure. The concentration of the total soluble phosphate was very low, down to $5 \mu \mathrm{M}$, which was admitted at least at low $\mathrm{pH}$ because of this large surface area. The in situ ATR- FTIR method used is also advantageous compared to batch methods since it admits molecular level information of adsorbed species in real time. These advantages facilitated the study of aqueous phosphate adsorption onto mesoporous alumina at both low and high $\mathrm{pH}$ and in the concentration range $5 \mu \mathrm{M}$ to $2000 \mu \mathrm{M}$. The objective of the study was to elucidate the structure of complexes formed upon phosphate adsorption on alumina as functions of $\mathrm{pH}$ and phosphate concentration and to be able to suggest a possible sorption mechanism based on collected infrared spectroscopic data.

\section{Results and Discussions Characterization}

Information about structure and surface area of the synthesized mesoporous alumina was obtained from X-Ray Diffraction (XRD) analysis and $\mathrm{N}_{2}(\mathrm{~g})$ adsorption/desorption measurements, respectively. The results showed that the synthesized alumina material had a high surface area viz. $329 \mathrm{~m}^{2} \cdot \mathrm{g}^{-1}$. The pore size was centered at $9.5 \mathrm{~nm}$ with a narrow distribution as shown in Additional file 1: Figure S1 (supporting information) and the pore volume was 0.88 $\mathrm{cm}^{3} \mathrm{~g}^{-1}$. XRD analysis of the synthesized mesoporous alumina sample is presented in Additional file 1: Figure S2, which confirmed the $\gamma-\mathrm{Al}_{2} \mathrm{O}_{3}$ structure [30] (PDF No. 791558). The synthesized alumina was dispersed in $0.01 \mathrm{M}$ $\mathrm{NaCl}$ aqueous solution, prepared using Milli-Q water, and deposited on a ZnSe ATR crystal for FTIR measurements. The resulting adsorbent layer is shown in Figure 1. The top-view of the Scanning Electron Microscopy image in Figure 1 shows small alumina particles $(20-30 \mathrm{~nm}$ in diameter) as well as agglomerated particles. The thickness of the deposited alumina layer was around $4 \mu \mathrm{m}$, as judged from the side-view image. The distinctly white part is fractures from the substrate.

It is well-known that upon attenuated total reflection at the surface of an ATR crystal, the electric field will decline exponentially with the distance from the crystal surface. Accordingly, phosphate adsorbed in the mesoporous alumina layer closer to the reflecting surface will contribute more to the recorded infrared absorption than phosphate species adsorbed in the outer part of the detection volume. The penetration depth is the distance from the crystal surface where the electric field has dropped to $\mathrm{e}^{-1}$ of its value but the electric field is of course larger than zero also beyond that distance. For a $\mathrm{ZnSe}$ crystal, the penetration depth is $\sim 1.6 \mu \mathrm{m}$ at 1000 $\mathrm{cm}^{-1}$ provided the refractive index of the porous alumina layer in water is $\sim 1.4$. However, a deposited layer thicker than the penetration depth is rather an advantage here since the intensity recorded from adsorbed species will not be much influenced by the layer being $3 \mu \mathrm{m}$ or $5 \mu \mathrm{m}$ thick.

\section{Effect of $\mathrm{pH}$ and concentration on phosphate sorption}

Figure 2 shows spectra of phosphate sorbed onto $\gamma$-alumina from $50 \mu \mathrm{M}$ aqueous phosphate solution at various $\mathrm{pH}$. The integrated infrared absorption between 1250 and 850 $\mathrm{cm}^{-1}$, which corresponds to the stretching frequency region of phosphate species is related to the amount of adsorbed phosphate. The spectral intensity increased from $\mathrm{pH}$ of 9.0 to $\mathrm{pH}$ of 4.05 , indicating that acidic $\mathrm{pH}$ favors phosphate adsorption in accordance with previous studies. The spectral line shape changed and the peak position shifted from $1056 \mathrm{~cm}^{-1}$ at $\mathrm{pH} 9.0$ to $1090 \mathrm{~cm}^{-1}$ at $\mathrm{pH} 4.05$. In addition, a new strong band appeared at $1020 \mathrm{~cm}^{-1}$. It is clear from this figure that the amount of phosphate adsorbed increased with decreasing $\mathrm{pH}$.

Figure 3 shows infrared spectra of phosphate sorbed onto $\gamma$-alumina from $1000 \mu \mathrm{M}$ and $500 \mu \mathrm{M}$ aqueous phosphate solutions at $\mathrm{pH} 4.1$ and $\mathrm{pH}$ 9.0. According to Figure 3 , the band intensity increased with the phosphate concentration in solution. At each of the two $\mathrm{pH}$ values, the line shapes of the infrared bands are very similar at the two phosphate concentrations shown although the bands became broader at higher concentration. The band intensity increased much faster with time upon sorption 

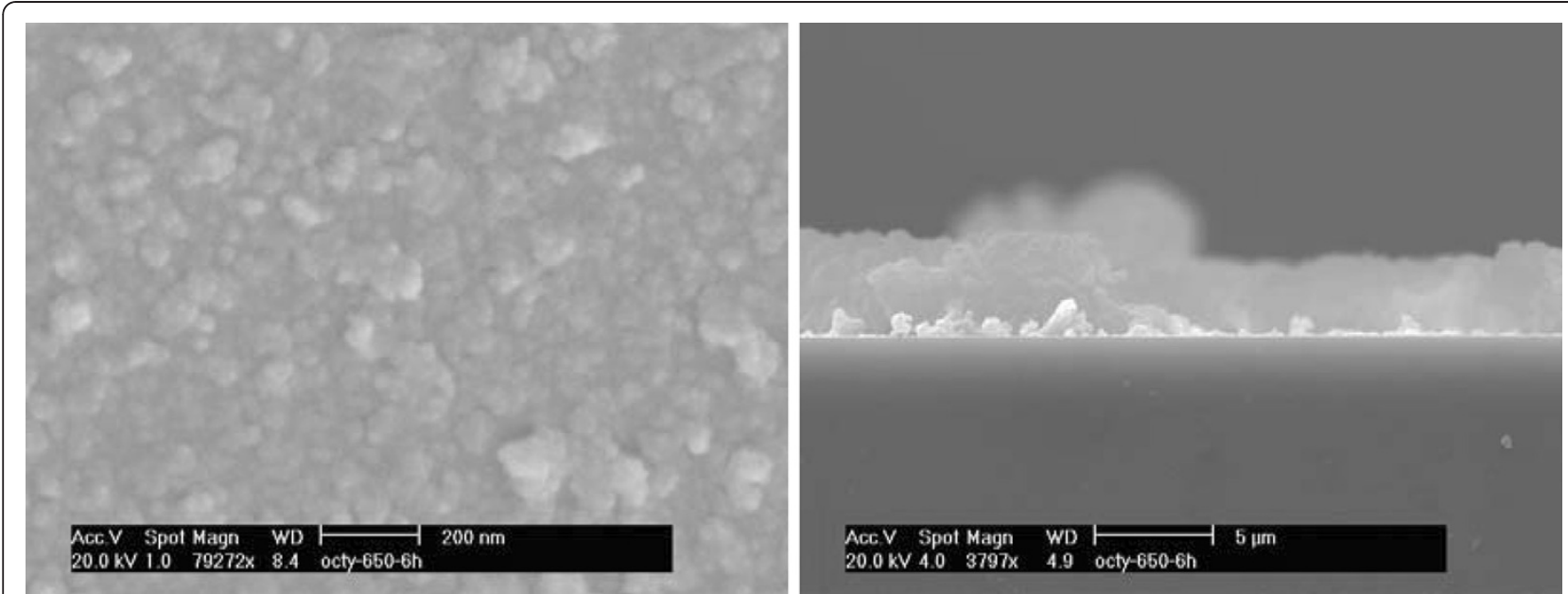

Figure 1 SEM images of mesoporous alumina deposited on a glass plate (left) top view and (right) side view. Same amount of adsorbent was deposited on the ATR crystal in the sorption experiments.

from a phosphate solution at $\mathrm{pH} 4.1$ compared with sorption at $\mathrm{pH}$ 9.0. However, the amount of adsorbed phosphate did not reach an equilibrium plateau value but rather a constant slow increase in the adsorbed amount with time $(\sim 2 \%$ in spectral intensity at $\mathrm{pH} 4.1)$. This increase with time may be due to the formation of aluminum phosphate. The increase with time was smaller at $\mathrm{pH} 9.0$ compared with $\mathrm{pH} 4.1$ and the beginning of the constant adsorption rate region was used for a Langmuir type of data evaluation. The onset of this region was assumed to represent an equilibrium sub-monolayer adsorption of phosphate.

As calculated from the thermodynamic equilibrium constants, $\mathrm{H}_{2} \mathrm{PO}_{4}^{-}$and $\mathrm{HPO}_{4}^{2-}$ are the dominating species in solution at $\mathrm{pH} 4.1$ and 9.0, respectively (see Additional file

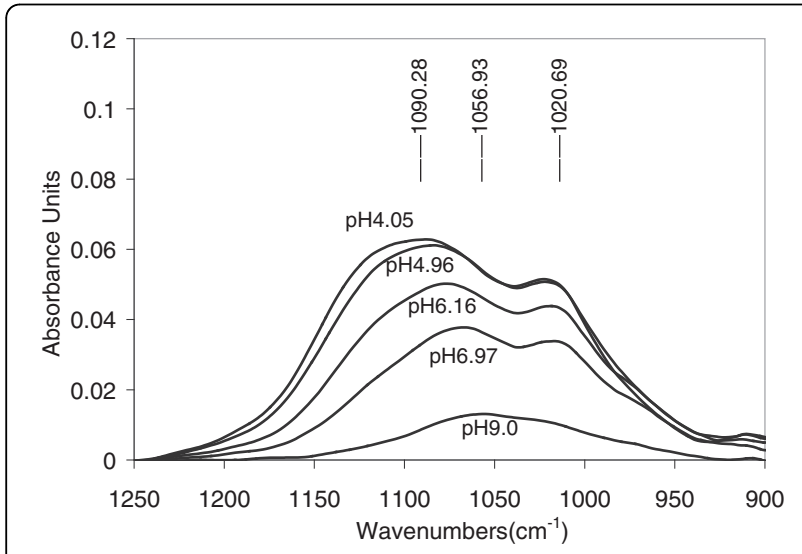

Figure 2 Infrared spectra showing phosphate adsorbed on mesoporous $\gamma$-alumina from a $0.050 \mathrm{mM}$ aqueous phosphate solution at pH: 4.05, 4.96, 6.16, 6.97, and 9.0. The absorption intensity decreased with increasing $\mathrm{pH}$.
1: Figure S3). Therefore, the relative amounts of adsorbed phosphate at the two $\mathrm{pH}$ values could be estimated assuming that equal amounts of $\gamma-\mathrm{Al}_{2} \mathrm{O}_{3}$ was penetrated in each experiment, which also was supported by the $\mathrm{pH}$-envelope experiments where the same alumina layer was exposed to phosphate in solution starting at $\mathrm{pH} 9.0$ and ending at $\mathrm{pH}$ 4.1 (see Figure 2). A layer thickness larger than the penetration depth seems to facilitate this estimation. However, it is not straight forward to compare the amount of adsorbed $\mathrm{H}_{2} \mathrm{PO}_{4}^{-}$and the amount of absorbed $\mathrm{HPO}_{4}^{2-}$ because the transition moments of the two adsorbed species may be different implying different absorption coefficients. To approach this problem, the absorption of the two species in solution was compared. It turned out that the same concentration $(10000 \mu \mathrm{M})$ of the two species resulted in a slightly higher integrated absorbance for $\mathrm{HPO}_{4}^{2-}$ as compared with $\mathrm{H}_{2} \mathrm{PO}_{4}^{-}$and that the splitting of the $v_{3}$ vibration is different because of different symmetries $\left(\mathrm{C}_{3 v}\right.$ and $\left.\mathrm{C}_{2 v}\right)$. According to the Beer-Lambert Law, it implies that the absorption coefficient for $\mathrm{H}_{2} \mathrm{PO}_{4}^{-}$in solution should be slightly lower than this coefficient for $\mathrm{HPO}_{4}^{2-}$ in solution. A first assumption would be that the absorption coefficients of these two species, when forming surface complexes, are either close to similar or the coefficient of adsorbed $\mathrm{H}_{2} \mathrm{PO}_{4}^{-}$is rather lower than the corresponding coefficient for adsorbed $\mathrm{HPO}_{4}^{2-}$. In either case, it seems reasonable to suggest that the amount of phosphate adsorbed at the lower $\mathrm{pH}$ value is much larger than the amount adsorbed at the higher $\mathrm{pH}$ value as indicated in Figure 3.

This relation between the two adsorbed species at low and high $\mathrm{pH}$ is also supported by batch experiments [11]. It is also supported by Johnson et al. in their study of phosphate adsorption onto $\gamma$ - $\mathrm{Al}_{2} \mathrm{O}_{3}$ using NMR spectroscopy [28]. The latter investigation indicates that the amount of 


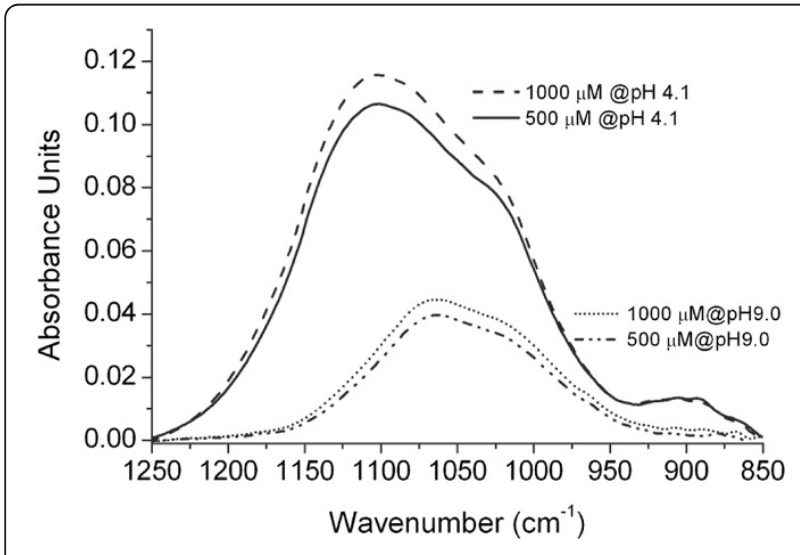

Figure 3 Infrared spectra of sorbed phosphate recorded from 1.0 $\mathrm{mM}$ and $0.5 \mathrm{mM}$ aqueous phosphate solutions onto $\gamma$-alumina. The two upper curves are recorded at $\mathrm{pH}=4.1$ (after $20 \mathrm{~min}$ ) and the lower curves at $\mathrm{pH}=9.0$ (after $20 \mathrm{~min}$ ).

phosphate adsorbed at the lower $\mathrm{pH}$ should be about a factor of two larger than at the higher $\mathrm{pH}$ value, compared to a factor of about 3 estimated from our infrared spectra (Figure 3) assuming that the ratio between the absorption coefficients for the two species in solution is similar to the adsorbed species. It is clear from these comparisons that the transition moments of the phosphate species in solution change upon adsorption.

\section{Spectral simulation}

The line shape of the infrared absorption representing adsorbed $\mathrm{H}_{2} \mathrm{PO}_{4}^{-}$resulted in five sub-bands, as obtained by the band simulation. This is shown in Figure 4, where the spectral line shape of phosphate adsorbed from $500 \mu \mathrm{M}$ phosphate solution at $\mathrm{pH} 4.1$ was simulated by curve fitting. The five sub-bands were centered at the frequency positions 1126, 1080, 1017, 959, and $901 \mathrm{~cm}^{-1}$. However, five sub-bands is at least one too many since both $\mathrm{C}_{2 v}$ and $\mathrm{C}_{1}$ symmetry is expected to result in three bands from the triply degenerate asymmetric stretching and one band from the active symmetric stretching of the phosphate entity. Alternatively, the bands may be caused by simultaneous detection of both inner-sphere and outer-sphere complexes.

Excluding the band at $1080 \mathrm{~cm}^{-1}$, this result is fairly consistent with previous studies of phosphate adsorption onto, ferrihydrite [16], hematite [17] and goethite [18] from aqueous solution, which suggested that the dominant surface complex at low $\mathrm{pH}$ was $(\mathrm{FeO})_{2}-\mathrm{PO}-\mathrm{OH}$. The $v_{3}$ peak positions in these studies were obtained at about 1120, 1006, and $970 \mathrm{~cm}^{-1}$, where the highest frequency was assigned to a mode involving the $\mathrm{P}=\mathrm{O}$ double bond. Some difference in frequency positions, compared to alumina, was expected since the adsorption sites are represented by two different metal atoms although the valence of the two is identical.
However, according to our findings there is also an absorption band located at $\sim 1080 \mathrm{~cm}^{-1}$ that may not to be due to the splitting of the $v_{3}$ vibration. According to calculations using density functional theory (DFT) by Kwon and Kubicki [29] on phosphate adsorbed onto iron hydroxides, the most probable structure was found to be a diprotonated bidentate binuclear complex at low pH $(4.2-5.7)$. The calculated vibration frequencies showed for example absorptions at 1120, 1080, 993, and $940 \mathrm{~cm}^{-1}$. Comparing our experimental results for the adsorption of phosphate onto mesoporous alumina with results from computed infrared frequencies from phosphate adsorbed on iron oxide [29] and experimental results from phosphate adsorption onto iron oxides [16-18], the diprotonated bidentate binuclear complex was excluded. There are well documented experimental results showing that the frequency appearing at $1126 \mathrm{~cm}^{-1}$ in our experimental spectra should be mainly due to the $\mathrm{P}=\mathrm{O}$ entity. Accordingly, the dominating surface complex at $\mathrm{pH} 4.1$ would be a monoprotonated bridging complex or a diprotonated monodentate complex. Moreover, the calculated frequencies of the monoprotonated bridging phosphate complex with Fe-hydroxide implied an absorption at 1113 $\mathrm{cm}^{-1}$, which is close to the expected frequency of the $\mathrm{P}=\mathrm{O}$ stretch that should show up in this surface complex. The difference from our experimental value $\left(1126 \mathrm{~cm}^{-1}\right)$ is about $1 \%$, which to our experience is very small, especially since the surface site atoms are different (Fe instead of $\mathrm{Al}$ ). Due to the appearance of the latter frequency in our spectra at low $\mathrm{pH}$, it seems reasonable to suggest that the surface complex formed between mesoporous $\gamma-\mathrm{Al}_{2} \mathrm{O}_{3}$ and phosphate at low $\mathrm{pH}$ is a monoprotonated bidentate binuclear $(\mathrm{AlO})_{2}-\mathrm{PO}-\mathrm{OH}$ complex or a diprotonated monodentate complex. The sub-band at $1080 \mathrm{~cm}^{-1}$ should at least partly be due to precipitated aluminum phosphate. In a separate

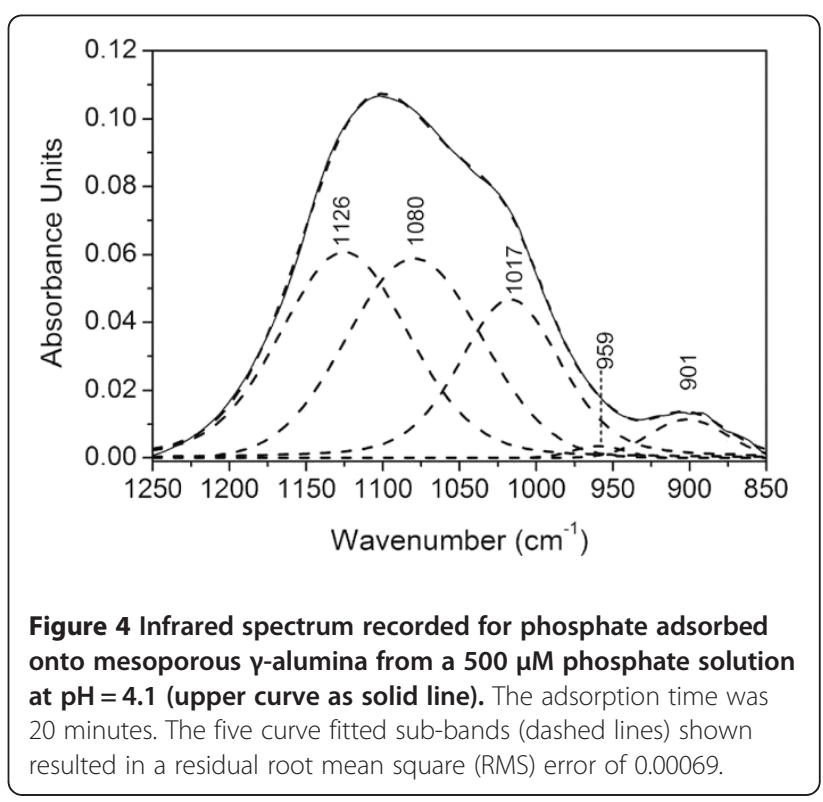


experiment the infrared spectrum of $\mathrm{AlPO}_{4} \mathrm{nH}_{2} \mathrm{O}$ was recorded. A broad infrared absorption was obtained with maximum absorbance at $\sim 1087 \mathrm{~cm}^{-1}$. Subtraction of this band from the total band shape in Figure $4(\mathrm{pH} 4.1)$, resulted in only minor wavenumber shifts of the simulated bands but in addition a band of low intensity appeared at about $1250 \mathrm{~cm}^{-1}$. The latter band may be due to PO-H bending vibration indicating that the complex formed is protonated.

Figure 5 shows the simulated bands for phosphate adsorption from a $500 \mu \mathrm{M}$ phosphate solution at $\mathrm{pH} 9.0$ after 20 minutes of sorption. The curve fitted sub-bands were located at 1062, 1006, and $970 \mathrm{~cm}^{-1}$. The number of subbands at higher frequency than $900 \mathrm{~cm}^{-1}$ was reduced from four to three, without any contribution from precipitated aluminum phosphate at $1087 \mathrm{~cm}^{-1}$, which means that from a symmetry point of view the surface complexes would have $\mathrm{C}_{2 v}$ or $\mathrm{C}_{1}$ symmetry at $\mathrm{pH}$ 9.0. However, at this $\mathrm{pH}$ the band at $1120 \mathrm{~cm}^{-1}$, corresponding to $\mathrm{P}=\mathrm{O}$ stretching, is missing and therefore a nonprotonated bidentate binuclear or a monoprotonated monodentate complex seems to be the most reasonable phosphate configurations at the mesoporous $\gamma$-alumina surface.

It may be added that normalized absorbance spectra (not shown) recorded for phosphate concentrations from $5 \mu \mathrm{M}$ to $2000 \mu \mathrm{M}$ (at pH 4.1) showed that; the peak frequency shifted to higher wavenumber $\left(\sim 15 \mathrm{~cm}^{-1}\right)$, the infrared bands became slightly broader with increasing phosphate concentration, and that the increased halfwidth was caused by an increased broadening only on the high wavenumber side of the band. The shift of the peak frequency became evident at high phosphate concentration (see Additional file 1: Figure S5). The reason for this change of the line shape at high phosphate concentration is ascribed to aluminum phosphate precipitation, as discussed below.

\section{Sorption isotherm}

The integrated absorption as a function of concentration at each of the two $\mathrm{pH}$ values is plotted in Figure 6. It was evident that the amount of phosphate adsorbed on aluminum oxide increased with increasing phosphate concentration but the increments between equilibrium plateau values became gradually smaller at higher concentrations. The adsorption data were adapted to the Langmuir and Freundlich isotherm models, as shown in Figure 6(A) and (B). Evidently, the adsorption data fits better to the Langmuir isotherm in the low concentration range and the Freundlich isotherm at higher concentrations although the latter isotherm seems to be more suitable to describe the adsorption behavior for the whole concentration range. Guan et al [31] suggested that the Freundlich isotherm model indicates the heterogeneity of the adsorbent. In our study, this adsorption

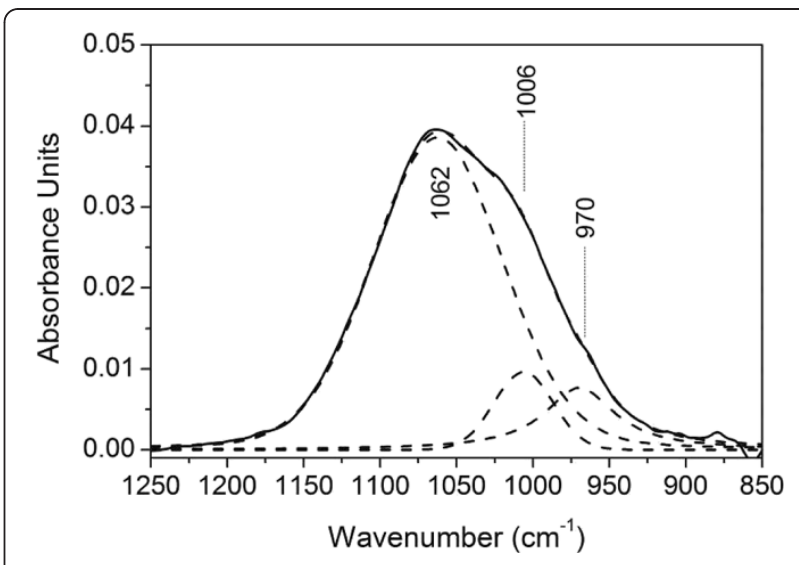

Figure 5 The infrared band of phosphate adsorbed onto $\gamma-\mathrm{Al}_{2} \mathrm{O}_{3}$ from an aqueous $0.5 \mathrm{mM}$ phosphate solution at $\mathrm{pH} 9.0$ after 20 minutes of adsorption. The fitted sub-bands resulted in a RMS error of 0.0004 .

behavior was obtained irrespective of the amount of $\gamma$ alumina deposited on the ATR crystal. Comparing the integrated absorbencies, the amount of phosphate adsorbed at $\mathrm{pH} 4.1$ was about 3 times as high as the amount adsorbed at $\mathrm{pH}$ 9.0. The reduced adsorption of phosphate at $\mathrm{pH} 9.0$ is most likely due to the absence of $\equiv \mathrm{AlOH}_{2}^{+}$sites and the formation of $\equiv \mathrm{AlO}^{-}$sites at the higher $\mathrm{pH}$ value. The adsorbate is negatively charged at both $\mathrm{pH} 4.1$ and 9.0. Figure 7 shows a few more or less realistic molecular symmetries that are possible for the $\mathrm{Al}-\mathrm{P}$ complexes.

The adsorption of phosphate at the surface of alumina has been studied by different methods and the proposed types of binding differ from monodentate to bidentate upon varying the solution $\mathrm{pH}$ and surface coverage. However, it seems that the monodentate type of phosphate binding to the aluminum and iron oxide surface is often suggested [32]. For example in the adsorption of phenyl phosphonic acid on the alumina surface a strong adsorption was observed at $\mathrm{pH}<7$, whereas a strong decrease in adsorption affinity was observed within the approximate $\mathrm{pH}$ range of $7.7-9.5$ [33], The results of phosphate adsorption at the surface of $\gamma-\mathrm{Al}_{2} \mathrm{O}_{3}$ in this study showed a tendency similar to that of the adsorption of phenyl phosphonic acid onto alumina, although phosphate here was still adsorbed at the higher $\mathrm{pH}$ limit. However, the lack of a band due to $\mathrm{P}=\mathrm{O}$ stretching at high $\mathrm{pH}$ suggests a bidentate bridging or a monodentate type of binding upon increasing the solution $\mathrm{pH}$. The monodentate type of complex might be preferred since a free rotation about the $\mathrm{Al}-\mathrm{O}$ bond may facilitate hydrogen bonding interaction.

Taking all these pieces of information into account, including the higher density of adsorbed phosphate at low $\mathrm{pH}$, it is suggested that the inner-sphere surface complex between phosphate and the current alumina surface is of 


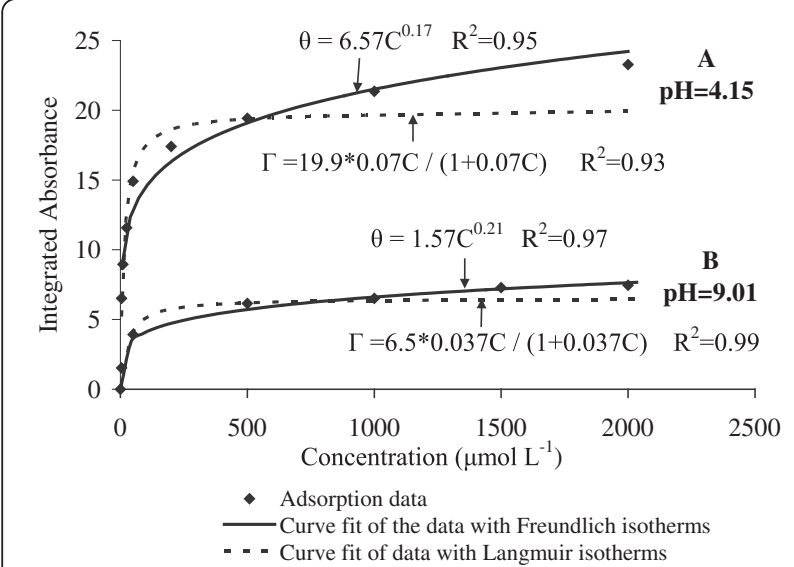

Figure 6 Adsorption isotherms of phosphate at pH 4.1 (A) and 9.0 (B) upon adsorption at the water-mesoporous $\gamma$-alumina interface. The solid and dotted lines are the results of fitting using the Freundlich and the Langmuir models, respectively. IA denotes Integrated Absorbance.

the diprotonated monodentate type or a monoprotonated bidentate binuclear complex at $\mathrm{pH} 4$. In addition, precipitated aluminum phosphate seemed to be formed at this $\mathrm{pH}$, which also is in accordance with results from previous NMR measurements [28]. At a $\mathrm{pH}$ value of 9, the infrared spectra of the adsorbed complexes are in accordance with a nonprotonated bidentate binuclear or a monoprotonated monodentate configuration.

\section{Mechanism of sorption}

As already pointed out the amount of phosphate adsorbed at $\mathrm{pH} 4.1$ is about 3 times as large as the amount adsorbed at pH 9.0 (Figure 3). This is supported by the simulation of the protonation state of adsorbent surface sites (as shown in Additional file 1: Figure S4), suggesting that the number of $\equiv \mathrm{AlOH}_{2}^{+}$sites at the solid surface is reduced substantially upon increasing the solution $\mathrm{pH}$ from 4.1 to 9.0 and therefore the observed reduced intensity of adsorbed phosphate at the higher $\mathrm{pH}$ value might be explained by the reduced availability of positive adsorption sites along with an increasing number of negatively charged surface sites (see Additional file 1: Figure S4).

However, the ratio between the amount of adsorbed phosphate at $\mathrm{pH} 4.1$ and $\mathrm{pH} 9.0(\sim 3)$ increases with the bulk concentration of phosphate (Figure 6) largely caused by the increased infrared intensity with phosphate concentration, at $\mathrm{pH}$ 4.1. This increase in intensity can not be due to infrared absorption from anions in bulk solution considering the thick $(\sim 4 \mu \mathrm{m})$ alumina layer on the ATR crystal, but could be interpreted as an increased aluminum phosphate precipitation.
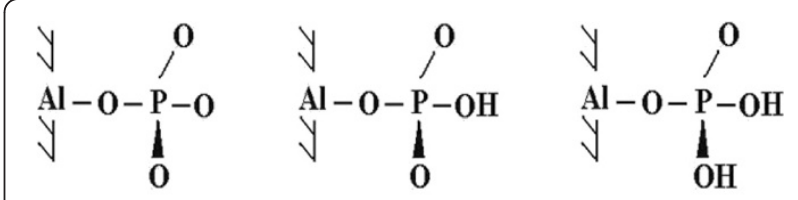

$$
\begin{aligned}
& \text { a. } \mathrm{C}_{3 v} \\
& y \\
& \mathrm{Al}-0>\mathrm{P}^{-} \\
& \mathrm{Al}-0>\mathrm{O}^{-} \\
& y \\
& \text { d. } \mathrm{C}_{2 v}
\end{aligned}
$$$$
\text { b. } \mathrm{C}_{1}
$$$$
\text { c. } \mathrm{C}_{1}
$$<smiles>CC12CCC[Al]1OP(=O)(O)O2</smiles>

Figure 7 Possible molecular configurations of $\mathrm{P}$ inner-sphere complexes on the alumina-water interface at various $\mathrm{pH}$ values; a) nonprotonated monodentate, b) monoprotonated monodentate, c) diprotonated monodentate, d) nonprotonated bidentate binuclear, e) monoprotonated bidentate binuclear.

It seems also reasonable to assume that phosphate entities in solution take part in hydrogen bonding to already adsorbed inner-sphere complexes thereby forming outersphere complexes. Most likely the negatively charged part of the $\mathrm{H}_{2} \mathrm{PO}_{4}^{-}$entity takes part in this interaction with the diprotonated or monoprotonated non-charged surface complexes. The hydrogen bonded $\mathrm{H}_{2} \mathrm{PO}_{4}^{-}$anion has $\mathrm{C}_{2 \mathrm{v}}$ symmetry in aqueous solution since three $\mathrm{v}_{3}$ bands were observed at 1159, 1074, and $939 \mathrm{~cm}^{-1}$. The $1074 \mathrm{~cm}^{-1}$ band had the strongest absorbance.

The symmetry and the peak positions are expected to be the same when $\mathrm{H}_{2} \mathrm{PO}_{4}^{-}$is hydrogen bonded to an inner-sphere complex. Accordingly, the strong absorption at about $1080 \mathrm{~cm}^{-1}$ (Figure 4) may, in addition to precipitated aluminum phosphate, also be caused by contribution from hydrogen bonded phosphate species in outer-sphere position.

At pH 9.0, the surface complex is supposed to be nonprotonated or monoprotonated implying that the negatively charged surface complex offers hydrogen bonding possibilities to the proton of the $\mathrm{HPO}_{4}^{2-}$ anion. However, this interaction is prohibited by the repulsion between the negatively charged species adsorbed at the alumina surface and the anion dominating in the bulk solution $\left(\mathrm{HPO}_{4}^{2-}\right)$ and therefore the increase in bulk phosphate concentration does imply only a small increase in adsorbed amount of phosphate (Figure 6).

A support for this interpretation of the sorption mechanism at $\mathrm{pH} 9.0$ is the results from zeta potential measurements using the electrophoresis method. The results of the zeta potential of the synthesized mesoporous $\gamma-\mathrm{Al}_{2} \mathrm{O}_{3}$ in the absence and presence of phosphates as a function of $\mathrm{pH}$ are presented in Figure 8. 
These measurements showed that the iso-electric point (IEP) of the mesoporous alumina particles dispersed in aqueous $0.01 \mathrm{M} \mathrm{NaCl}$ solution was close to $\mathrm{pH} 9.0$. However, in a $5 \mu \mathrm{M}$ aqueous phosphate solution at $\mathrm{pH}$ 9.0, the zeta potential became negative $(-15 \mathrm{mV})$ and decreased to $-20 \mathrm{mV}$ in a $50 \mu \mathrm{M}$ solution. This finding became a support for the suggested surface complexes formed at $\mathrm{pH}$ 9.0. Furthermore, it offered an explanation to the sorption of negatively charged phosphate species at this $\mathrm{pH}$ since the alumina surface was about neutral to start with implying a large number of $\mathrm{OH}$ groups at the mesoporous surface. However, during the adsorption of phosphate the surface charge becomes more and more negative and accordingly the continued adsorption of negatively charged phosphate species should be increasingly prohibited at higher bulk concentrations of phosphate.

At $\mathrm{pH} 4.1$, the zeta potential measurements showed the alumina surface to be positively charged irrespective of the bulk concentration of phosphate being $5 \mu \mathrm{M}$ or 50 $\mu \mathrm{M}$. The zeta potential measured at $5 \mu \mathrm{M}(\sim 20 \mathrm{mV})$ only decreased by a few $\mathrm{mV}$ upon increasing the phosphate concentration to $50 \mu \mathrm{M}$. At this phosphate concentration the number of surface sites on the alumina surface (assuming 1 site per $\mathrm{nm}^{2}$ ) is far below the number of $\mathrm{H}_{2} \mathrm{PO}_{4}^{-}$units in the aqueous solution but the concentration of protons at this $\mathrm{pH}$ exceeds the concentration of phosphate anions $(50 \mu \mathrm{M})$ by a factor of 2 . However, it seems reasonable that the number of adsorbed species at $\mathrm{pH} 4.1$ is much larger than at $\mathrm{pH} 9.0$ since a positively charged surface should be more prone to accept negatively charged species.

\section{Experimental}

Synthesis and preparation of alumina layer for IR analysis

The hydrous mesoporous alumina was prepared by adding $\mathrm{NH}_{3} \cdot \mathrm{H}_{2} \mathrm{O}$ solution (2.5\%) slowly to a rapidly stirred $\mathrm{AlCl}_{3} \cdot 6 \mathrm{H}_{2} \mathrm{O}$ solution $\left(1 \mathrm{~mol} \cdot \mathrm{L}^{-1}\right)$. PEG (relative molecular mass $=4000)$ solution was used as a structure-directing reagent and as a dispersant to prevent the solid particles from aggregation. In addition dodecylamine was used as co-template. The suspension was centrifuged after being intensively stirred for $1 \mathrm{~h}$ at $\mathrm{pH}$ 9.0. The centrifugate was then rinsed with distilled water and ethanol in order to remove extra PEG and other impurities. The resulting gel was dissolved in ethanol solution and distilled at $100{ }^{\circ} \mathrm{C}$ to remove the alcohol. In the last step, mesoporous $\gamma$-alumina was obtained by calcination of the aluminum hydroxide powder at $650^{\circ} \mathrm{C}$ for 6 hours. The resulting adsorbent had a $\mathrm{N}_{2}$ BET surface area of $329 \mathrm{~m}^{2} / \mathrm{g}$, which may be compared with a common surface area of $\gamma-\mathrm{Al}_{2} \mathrm{O}_{3}$ offered by suppliers, viz. $140 \mathrm{~m}^{2} / \mathrm{g}$.

Stock alumina dispersions $\left(0.5 \mathrm{~g} \cdot \mathrm{L}^{-1}\right)$ were prepared by dispersing solid mesoporous $\gamma$-alumina in $0.01 \mathrm{M} \mathrm{NaCl}$

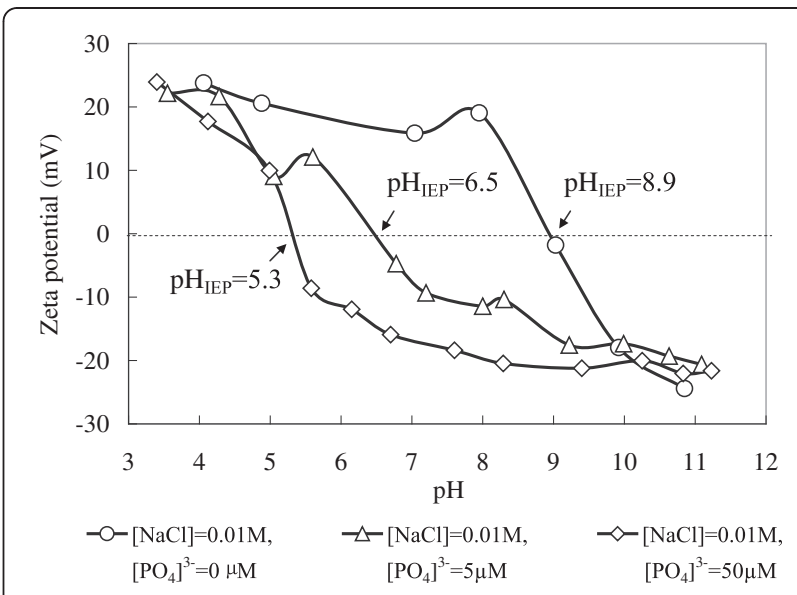

Figure 8 Zeta potential of mesoporous $\gamma-\mathrm{Al}_{2} \mathrm{O}_{3}$ in the absence and presence of phosphates. Phosphate concentrations and pH values are indicated.

solution. The resulting dispersion was shaken during one hour. $2.0 \mathrm{ml}(\approx 1 \mathrm{mg})$ of the alumina dispersion was evenly distributed over one side of the trapezoidal $(50 \mathrm{x}$ $20 \times 3 \mathrm{~mm}) \mathrm{ZnSe}$ ATR crystal $\left(45^{\circ}\right.$ bevel) by a pipettor and subsequently dried in air overnight to deposit a dry alumina layer. The oxide layer was then rinsed with water to eliminate the particles that were loosely adhered to the crystal.

\section{In situ ATR-FTIR measurements}

The experimental setup for in situ ATR measurements is described in more detail elsewhere [27]. The dimension of the ATR crystal and the experimental setup used allowed 10 reflections to penetrate the mesoporous layer. The refractive index of the $\mathrm{ZnSe}$ crystal was 2.41 implying a penetration depth of $1.6 \mu \mathrm{m}$ at $1000 \mathrm{~cm}^{-1}$ assuming a refractive index of 1.4 for the porous $\gamma-\mathrm{Al}_{2} \mathrm{O}_{3}$ phase on the crystal surface. Since the porous alumina layer is assumed to be penetrated by water, the refractive index of the alumina/water phase was estimated from the refractive index of water at $1084 \mathrm{~cm}^{-1}$ and the refractive index of $\gamma$-alumina (1.6). Data for the phosphate adsorption isotherm were obtained at fixed $\mathrm{pH}$ values of 9.0 and 4.1. Phosphate solutions were prepared from Milli-Q water and $\mathrm{NaH}_{2} \mathrm{PO}_{4} \mathrm{H}_{2} \mathrm{O}$ (Sigma-Aldrich). For these experiments, the alumina deposit was first equilibrated with $0.01 \mathrm{M} \mathrm{NaCl}$ as ionic medium adjusted to the $\mathrm{pH}$ of interest and subsequently a single beam background spectrum was recorded. Then, the aqueous phosphate solution was allowed to flow over the alumina layer at a rate of $1 \mathrm{~mL} \mathrm{m^{-1 }}(0.01 \mathrm{M} \mathrm{NaCl}$ as ionic medium). Spectra of phosphate adsorbed onto the alumina layer were recorded every ten minutes. After an initially fast 
adsorption, a constant slow adsorption rate was obtained, which was confirmed by the difference in the spectral intensities of two successive spectra (less than $2 \%)$. A small volume of concentrated phosphate stock solution was added to increase the phosphate concentration stepwise. The initial concentration of phosphate at each step was used for isotherm data evaluation, since the amount of phosphate in solution was in excess relative to the amount of surface sites, due to the small amount of alumina deposited. Assuming a surface site density of 1 site $/ \mathrm{nm}^{2}$, only for the lowest phosphate concentration $(5 \mu \mathrm{M})$ the number of phosphate entities in solution corresponds to the number of surface sites in the detection volume. The incremental increase in phosphate concentration or change of $\mathrm{pH}$ was accomplished through an external reaction vessel implying that a set of adsorption experiments could be performed on the same layer of $\gamma$-alumina.

Experiments using a non-coated $\mathrm{ZnSe}$ crystal indicated that contributions from aqueous phosphate to the IR spectrum became visible above the noise level only at solution concentrations higher than $1000 \mu \mathrm{M}$. However, the amount of $\gamma$-alumina deposited on the ATR crystal was large enough to prohibit most of the infrared field to reach into the bulk solution and therefore all spectra are dominated by absorptions caused by alumina-sorbed phosphate complexes with a negligible contribution from phosphate in the bulk. Infrared spectra were recorded on a Bruker 66v/S FTIR spectrometer equipped with a DTGS detector and at room temperature $\left(23 \pm 1^{\circ} \mathrm{C}\right)$ and atmospheric pressure using the double side forward-backward acquisition mode. A total number of 128 scans were signal-averaged using an optical resolution of $4 \mathrm{~cm}^{-1}$. The resultant interferogram was Fourier transformed using the Mertz phase correction mode, a Blackman-Harris 3-term apodization function, and a zero filling factor of 2 . The recorded intensity of adsorbed phosphate at each bulk concentration was determined by integrating the absorption due to phosphate between $1250 \mathrm{~cm}^{-1}$ and $850 \mathrm{~cm}^{-1}$.

\section{Zeta potential measurements}

The zeta potential measurements were carried out on mesoporous $\gamma$-alumina sample using Zeta Compact zeta potential analyzer (CAD, France). An aliquot of the sample suspension with or without phosphate was dispersed in $40 \mathrm{~mL} \mathrm{NaCl}$ solution. The concentration of $\gamma$-alumina in the dispersion was ca. $5 \mathrm{mg} \cdot \mathrm{L}^{-1}$. The $\mathrm{pH}$ was adjusted with diluted $\mathrm{NaOH}$ and $\mathrm{HCl}$ solution. The conditioning time corresponds to that of FTIR measurements. After conditioning, the solution $\mathrm{pH}$ was measured and the electrophoretic mobility of particles was recorded and further processed by the Zeta 4 software applying the Smoluchowski equation. For each sample, the measurement was repeated three times and the final zeta potential was calculated as an average of the obtained values.

\section{Speciation modeling}

The speciation modeling of phosphate species in solution was carried out using computer program MEDUSA and the relevant equilibrium constants were collected from the MEDUSA database [34]. The speciation of mesoporous $\gamma-$ alumina surfaces was obtained using computer software WinSGW [35]; the surface acid base equilibrium constant for mesoporous $\gamma$-alumina was taken from our own published results [36].

\section{Conclusions}

Adsorption of phosphate onto synthesized mesoporous $\gamma$ alumina was characterized at acid $(\mathrm{pH} 4.1)$ and basic $\mathrm{pH}$ (9.0) by in-situ ATR-FTIR spectroscopy. The results indicated that different phosphate surface complexes were formed at the two $\mathrm{pH}$ values. At low $\mathrm{pH}$, infrared spectra could be interpreted as a diprotonated monodentate inner-sphere complex formed together with outer-sphere complexes hydrogen bonded to the already formed innersphere complexes. However, a monoprotonaded bidentate binuclear inner-sphere complex with the same symmetry could not be excluded implying that both types of innersphere complexes can appear simultaneously on the $\gamma$-alumina surface. In addition, precipitated $\mathrm{AlPO}_{4} \mathrm{nH}_{2} \mathrm{O}$ was formed on the $\gamma$-alumina surface at this low $\mathrm{pH}$ and started to form already in the beginning of the adsorption reaction as judged from the smooth change of the band shape with increasing phosphate concentration.

The amount of adsorbed phosphate increased rapidly at high phosphate concentrations and short reaction times followed by slow and small constant increase at longer reaction times. At $\mathrm{pH} 4.1$ an equilibrium plateau value was not reached even at long reaction times $(>300 \mathrm{~min}$ ) probably due to precipitation of aluminum phosphate.

At $\mathrm{pH}$ 9.0, the amount of adsorbed phosphate was only about $33 \%$ of the amount adsorbed at $\mathrm{pH} 4.1$, provided the transition moment of the surface complexes formed at the two $\mathrm{pH}$ values are about similar. This difference in adsorbed amount increased slightly at higher bulk phosphate concentrations $(>500 \mu \mathrm{M})$.

At the highest $\mathrm{pH}$ value studied here ( $\mathrm{pH} 9.0)$, the surface complex formed at pH 9.0 was most likely a non-protonated bidentate binuclear complex with $C_{2 v}$ symmetry or a monoprotonated monodentate complex $\left(C_{1}\right)$. From our infrared spectra it was not possible to differentiate between these two types of complexes. At this high $\mathrm{pH}$ there was no indication of precipitated $\mathrm{AlPO}_{4}$ probably due to an increase in the solubility of aluminium phosphate with increasing $\mathrm{pH}$ in combination with the detection limit of the spectroscopic method used. 
The adsorption of phosphate at the two $\mathrm{pH}$ conditions could be well described with the Langmuir type of adsorption isotherm at low concentrations and the empirical Freundlich adsorption isotherm for the whole concentration range, viz. $5-2000 \mu \mathrm{M}$.

\section{Additional file}

Additional file 1: Figure S1. Adsorption/desorption isotherms and pore diameter distribution of the synthesized mesoporous alumina sample. Figure S2. XRD results of the synthesized mesoporous alumina sample, which shows clearly the characteristic peaks of gamma-Al2O3 (PDF No. 79-1558). Figure S3. Distribution of aqueous $\mathrm{H}_{n} \mathrm{PO}_{4}{ }^{\mathrm{n}-3}$ species at different $\mathrm{pH}$, it can be seen that at $\mathrm{pH} 4$, the dominating solution species is $\mathrm{H}_{2} \mathrm{PO}_{4}^{-}$and at $\mathrm{pH} \sim 9$ the dominating solution species is $\mathrm{HPO}_{4}^{2-}$. Figure $\mathrm{S} 4$. Surface species distribution of aluminum oxide in solution.

\section{Competing interests}

The authors declare that they have no competing interests.

\section{Authors' contributions}

TZ carried out most experiments; ZS has formulated the research idea, drafted the manuscript and finalized the manuscript; $X Y$ has assisted to carry out the measurement of ATR-FTIR; AH has assisted to write considerable amount of text and explained the ATR-FTIR spectra. All authors read and approved the final manuscript.

\section{Acknowledgement}

Financial support from National Basic Research Program of China (No. 2011CB933700) and Chinese Natural Science Foundation (No.50874052; No. 20677022; 20810102001) is gratefully acknowledged.

\section{Author details}

${ }^{1}$ School of Chemistry and Chemical Engineering, University of Jinan, 250022 Jinan, China. ${ }^{2}$ Division of Chemical Engineering, Luleå University of Technology, S-971 87 Luleå, Sweden. ${ }^{3}$ Research Center for Eco-Environmental Sciences, Chinese Academy of Sciences, Beijing, China.

Received: 11 January 2012 Accepted: 23 March 2012 Published: 3 April 2012

\section{References}

1. Zhou QX, Gibson CE, Zhu YM: Evaluation of phosphorus bioavailability in sediments of three contrasting lakes in China and the UK. Chemosphere 2001, 42:221-225.

2. Correll DL: The role of phosphorus in the eutrophication of receiving waters: a review. J Environ Qual 1998, 27:261-266.

3. Stumm W: Significance of phosphorus in lakes and coastal water sediments and benthos. Water Res 1973, 7:129. Stumm W: The acceleration of the hydrogeochemical cycling of phosphorus. Water Research 1973, 7: 131-140.

4. Arai $Y$, Sparks DL: Phosphate reaction dynamics in soils and soil components: A muiltiscale approach. Adv Agron 2007, 94:135-179.

5. Stumm W: Reactivity at the mineral-water interface: dissolution andinhibition. Colloids Surf A 1997, 120:143-166.

6. Frost Rl, Kloprogge JT, Russell SC, Szetu JL: Vibrational spectroscopy and dehydroxylation of aluminum (oxo) hydroxides: gibbsite. App/ SpectrosC 1999, 53:423-434.

7. Frost Rl, Kloprogge JT, Russell SC, Szetu JL: Dehydroxylation of aluminium (oxo)hydroxides using infrared emission spectroscopy. Part II: Boehmite. App/ Spectrosc 1999, 53:572-582.

8. Dickie SA, McQuillan AJ: In-situ infrared spectroscopic studies of adsorption processes on boehmite particle films: exchange of surface hydroxyl groups observed upon chelation by acetylacetone. Langmuir 2004, 20:11630-11636

9. Yang XF, Sun ZX, Wang DS, Forsling W: Surface acid-base properties and hydration/dehydration mechanisms of aluminum (hydr)oxides. J Colloid Interface Sci 2007, 308:395-404.
10. Gan Y, Franks GV: Charging behaviour of gibbsite basal (001) surface in $\mathrm{NaCl}$ solution investigated by AFM colloidal probe technique. Langmuir 2006, 22:6087-6092.

11. Chen YSR, Butler JN, Stumm W: Adsorption of phosphate on alumina and kaolinite from dilute aqueous solutions. J Colloid Interface Sci 1973, 43:421-436

12. Chen YSR, Butler JN, Stumm W: Kinetic study of phosphate reaction with aluminum oxide and kaolinite. Environ Sci Technol 1973, 7:327-332.

13. Mikami N, Sasaki M, Hachiya K, Astumian RD, Ikeda T, Yasunaga T: Kinetics of the adsorption-desorption of phosphate on the gamma-alumina surface using the pressure-jump technique. J Phys Chem 1983, 87: 1454-1458.

14. Lijklema L: Interaction of orthophosphate with iron (III) and aluminium hydroxide. Environ Sci Technol 1980, 14:537-541.

15. Li W, Feng J, Kwon KD, Kubicki JD, Phillips BL: Surface speciation of phosphate on boehmite (gamma-AlOOH) determined from NMR spectroscopy. Langmuir 2010, 26:4753-4761.

16. Arai Y, Sparks DL: ATR-FTIR spectroscopic investigation on phosphate adsorption mechanisms at the ferrihydrite-water interface. J Colloid Interface Sci 2001, 241:317-326.

17. Elzinga EJ, Sparks DL: Phosphate adsorption onto hematite: An in situ ATR-FTIR investigation of the effects of $\mathrm{pH}$ and loading level on the mode of phosphate surface complexation. J Colloid Interface Sci 2007, 308:53-70.

18. Tejedor MI, Anderson MA: The protonation of phosphate on the surface of goethite as studied by CIR-FTIR and electrophoretic mobility. Langmuir 1990, 6:602-611.

19. Nero MD, Galindo $C$, Barillon $R$, Halter $E$, Madé $B$ : Surface reactivity of $\mathrm{a}-\mathrm{Al}_{2} \mathrm{O}_{3}$ and mechanisms of phosphate sorption: In situ ATR-FTIR spectroscopy and $\zeta$ potential studies. J Colloid Interface Sci 2010, 342: 437-444.

20. Zhu MX, Ding KY, Xu SH, Jiang X: Adsorption of phosphate on hydroxyl aluminum and hydroxyiron-montmorillonite complexes. J Hazard Mater 2009, 165:645-651.

21. Li L, Stanforth R: Distinguishing adsorption and surface precipitation of phosphate on goethite (a-FeOOH). J Colloid Interface Sci 2000, 230:12-21.

22. Laiti E, Persson P, Öhman LO: Surface complexation and precipitation at the $\mathrm{H}^{+}$- orthophosphate - aged gamma- $\mathrm{Al}_{2} \mathrm{O}_{3} /$ water interface. Langmuir 1996, 12:2969-2975.

23. Laiti E, Persson P, Öhman LO: Balance between surface complexation and surface phase transformation at the alumina/water interface. Langmuir 1998, 14:825-831.

24. Harvey OR, Rhue RD: Kinetics and energetics of phosphate sorption in a multi-component $\mathrm{Al}(\mathrm{III})-\mathrm{Fe}$ (III) hydr(oxide) sorbent system. J Colloid Interface Sci 2008, 322:384-393.

25. Luengo C, Brigante M, Antelo J, Avena M: Kinetics of phosphate adsorption on goethite: comparing batch adsorption and ATR-IR measurements. J Colloid Interface Sci 2006, 300:511-518.

26. Özacar M: Contact time optimization of two-stage batch adsorber design using second-order kinetic model for the adsorption of phosphate onto alunite. J Hazard Mater 2006, 137:218-225.

27. Yang XF, Roonasi P, Holmgren A: A study of sodium silicate in aqueous solution and sorbed by synthetic magnetite using in situ ATR-FTIR spectroscopy. J Colloid Interface Sci 2008, 328:41-47.

28. Johnson BB, Ivanov AV, Antzutkin ON, Forsling W: 31P nuclear magnetic resonance study of the adsorption of phosphate and phenyl phosphates on $\mathrm{y}-\mathrm{Al}_{2} \mathrm{O}_{3}$. Langmuir 2002, 18:1104-1111.

29. Kwon KD, Kubicki JD: Molecular orbital theory study on complexation structures of phosphates to iron hydroxides: calculation of vibrational frequencies and adsorption energies. Langmuir 2004, 20:9249-9254.

30. Sun ZX, Zheng $T$, Bo QB, Du M, Forsling W: Effects of calcination temperature on the pore size and wall crystalline structure of mesoporous alumina. J Colloid Interface Sci 2008, 319:247-251.

31. Guan XH, Shang C, Zhu J, Chen GH: ATR-FTIR investigation on the complexation of myo-inositol hexaphosphate with aluminum hydroxide. J Colloid Interface Sci 2006, 293:296-302.

32. Persson P, Nilsson N, Sjoberg S: Structure and bonding of orthophosphate ions at the iron oxide-aqueous interface. J Colloid Interface Sci 1996, 177:263-275.

33. Van Emmerik TJ, Sandstrom DE, Antzutkin ON, Angove MJ, Johnson BB: P-31 solid-state nuclear magnetic resonance study of the sorption of phosphate onto gibbsite and kaolinite. Langmuir 2007, 23:3205-3213. 
34. Puigdomenech I: MEDUSA chemical equilibrium software. Sweden: Royal Institute of Technology; 1999. Updated 18-Feb.-2004.

35. Purgel M, Takács Z, Jonsson CM, Nagy L, Andersson I, Bányai I, Pápai I, Persson P, Sjöberg S, Tóth I: Glyphosate complexation to aluminium (III). An equilibrium and structural study in solution using potentiometry, multinuclear NMR, ATR-FTIR, ESI-MS and DFT calculations. J Inorg Biochem 2009, 103:1426-1438.

36. Liu J, Zhang WM, Wu ZS, Qin LH, Sun RG, Sun ZX: Surface acid-base properties and adsorption behavior of heavy metal ions in aqueous suspensions of $\mathrm{a}-\mathrm{Fe}_{2} \mathrm{O}_{3}, \mathrm{Y}-\mathrm{Al}_{2} \mathrm{O}_{3}$ and their mixed system. Chin J Inorg Chem 2010, 26:1967-1974.

doi:10.1186/1752-153X-6-26

Cite this article as: Zheng et al:: Sorption of phosphate onto mesoporous $\gamma$-alumina studied with in-situ ATR-FTIR spectroscopy. Chemistry Central Journal 2012 6:26.

\section{Publish with ChemistryCentral and every scientist can read your work free of charge \\ "Open access provides opportunities to our colleagues in other parts of the globe, by allowing anyone to view the content free of charge." \\ W. Jeffery Hurst, The Hershey Company. \\ - available free of charge to the entire scientific community \\ - peer reviewed and published immediately upon acceptance \\ - cited in PubMed and archived on PubMed Central \\ - yours - you keep the copyright \\ Submit your manuscript here: \\ http://www.chemistrycentral.com/manuscript/<smiles>c1ccccc1</smiles> 